\title{
Preoperative right ventricular dysfunction should not preclude surgical ventricular restoration
}

\author{
Constantine L. Athanasuleas, MD, FACC
}

\footnotetext{
From the Division of Cardiothoracic Surgery, Department of Surgery, University of Alabama at Birmingham, Birmingham, Ala.

Disclosures: Author has nothing to disclose with regard to commercial support.

Received for publication Nov 14, 2016; accepted for publication Nov 17, 2016; available ahead of print Jan 7 , 2017.

Address for reprints: Constantine L. Athanasuleas, MD, FACC, Division of Cardiothoracic Surgery, University of Alabama at Birmingham, THT-720 1530 3rd Ave S, Birmingham, AL 35294 (E-mail: cathanasuleas@mac. com).

J Thorac Cardiovasc Surg 2017;153:853-4

$0022-5223 / \$ 36.00$

Copyright (c) 2016 by The American Association for Thoracic Surgery

http://dx.doi.org/10.1016/j.jtcvs.2016.11.042
}

The Surgical Treatment for Ischemic Heart Failure (STICH) trial concluded that adding surgical ventricular restoration (SVR) to coronary artery bypass grafting did not improve outcomes in the treatment of ischemic cardiomyopathy. ${ }^{1}$ The trial was controversial and contradicted extensive registry data. ${ }^{2}$ A subanalysis reported that preoperative right ventricular (RV) dysfunction occurred in $9 \%$ to $12 \%$ of patients and was associated with larger ventricles and worse early outcomes than seen with coronary artery bypass grafting alone. ${ }^{3}$ In this issue of the Journal, Couperus and colleagues ${ }^{4}$ report that preoperative RV dysfunction was even more frequent in patients undergoing SVR, as determined by RV fractional area change, $(21 \%)$ tricuspid annular plane systolic excursion (20\%), and RV longitudinal peak systolic strain (27\%). Any of these was present in 39\%. A higher number of impaired RV parameters worsened 30-day survival with heart failure as the cause of death. Antegrade cardioplegia was used in all patients. Couperus and colleagues ${ }^{4}$ concluded that refraining from SVR should be considered when RV dysfunction is present.

The cause of RV dysfunction in patients undergoing SVR and how operative technique may affect RV function can be understood by examining RV structure and function. The $\mathrm{RV}$ is composed of a free wall consisting of transverse muscle fibers at its base and a septum composed of helical fibers that are obliquely oriented. The transverse fibers constrict or compress to cause a bellows motion, which is responsible for about $20 \%$ of RV output, whereas the oblique septal fibers shorten and lengthen to produce $80 \%$ of RV systolic force. ${ }^{5,6}$ The septum is the main driver of RV function: when RV transverse fibers (free wall) are cauterized, ${ }^{7}$ or even removed and replaced with a patch, ${ }^{8}$ there is no RV dysfunction.

Septal fiber orientation affects biventricular function and explains how left heart failure begets right heart failure. 9,10 $^{-10}$ Septal viability is best determined by gadolinium-enhanced cardiovascular magnetic resonance imaging and might be a helpful tool in predicting reversibility of function. ${ }^{11}$

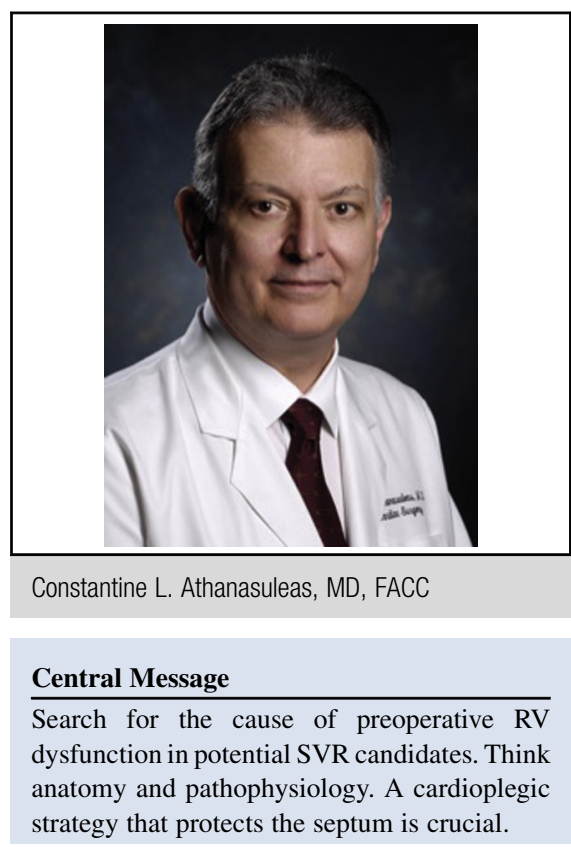

See Article page 845 .

Patients with preoperative RV failure without septal viability are not SVR candidates.

$\mathrm{RV}$ dysfunction is related to large hearts, and left ventricular volume reduction will improve longitudinal strain so long as the septum is not injured during surgery. Postoperative RV dysfunction has been reported in most patients after heart surgery ${ }^{12}$ and is an expression of impaired septal function (paradoxic septal motion) that is reported in $40 \%$ to $60 \%$ of patients undergoing heart surgery. ${ }^{13,14}$ Keyl and colleagues ${ }^{15}$ studied RV function in surgical aortic valve replacement and transcatheter replacement. In the surgical aortic valve replacement group, RV longitudinal contraction (tricuspid annular plane systolic excursion) decreased and RV transverse contraction increased with no net loss of RV function. In the transcatheter aortic valve replacement group, there were no changes in either parameter. This is likely because of inadequate myocardial protection at operation.

It has been proposed that septal dysfunction after cardiac surgery is related to inadequate myocardial protection and that it can be prevented by specific cardioplegic techniques. ${ }^{16}$ We have also shown that antegrade cardioplegia alone caused reduction in longitudinal strain, a variable that was normal after integrated antegrade and retrograde 
cardioplegia. The uninjured septum prevents RV dysfunction. $^{17,18}$

In the study of Couperus and colleagues, ${ }^{4}$ induced septal injury by inadequate myocardial protection may have worsened an already dysfunctional RV, which may explain the poor clinical outcomes. Preoperative RV dysfunction should not preclude SVR.

\section{References}

1. Jones RH, Velazquez EJ, Michler RE, Sopko G, Oh JK, O'Connor CM, et al. STICH Hypothesis 2 Investigators. Coronary bypass surgery with or without surgical ventricular reconstruction. $N$ Engl J Med. 2009;360:1705-17.

2. Buckberg GD, Athanasuleas CL. The STICH trial: misguided conclusions. J Thorac Cardiovasc Surg. 2009;138:1060-4.e2.

3. Kukulski T, She L, Racine N, Gradinac S, Panza JA, Velazquez EJ, et al. Surgical Treatment for Ischemic Heart Failure Investigators. Implication of right ventricular dysfunction on long-term outcome in patients with ischemic cardiomyopathy undergoing coronary artery bypass grafting with or without surgical ventricular reconstruction. J Thorac Cardiovasc Surg. 2015;149:1312-21.

4. Couperus LE, Delgado V, Palmen M, van Vessem ME, Braun J, Fiocco M, et al. Right ventricular dysfunction affects survival after surgical left ventricular restoration. J Thorac Cardiovasc Surg. 2017;153:845-52.

5. Sallin EA. Fiber orientation and ejection fraction in the human left ventricle. Biophys J. 1969;9:954-64.

6. Rushmer RF, Crystal DK, Wagner C. The functional anatomy of ventricular contraction. Circ Res. 1953;1:162-70.

7. Starr I, Jeffers WA, Meade RH Jr. The absence of conspicuous increments of venous pressure after severe damage to the right ventricle of the dog, with a discussion of the relation between clinical congestive failure and heart disease. Am Heart J. 1943;26:291-301.

8. Sawatani S, Mandell G, Kusaba E, Schraut W, Cascade P, Wajszczuk WJ, et al. Ventricular performance following ablation and prosthetic replacement of right ventricular myocardium. Trans Am Soc Artif Intern Organs. 1974;20 B: 629-36.

9. Saleh S, Liakopoulos OJ, Buckberg GD. The septal motor of biventricular function. Eur J Cardiothorac Surg. 2006;29(Suppl 1):S126-38.

10. Buckberg G, Nanda NC. Right ventricular changes after left-sided lesions: underlying cardiac mechanics. Echocardiography. 2015;32:727-30.

11. Ramani K, Judd RM, Holly TA, Parrish TB, Rigolin VH, Parker MA, et al. Contrast magnetic resonance imaging in the assessment of myocardial viability in patients with stable coronary artery disease and left ventricular dysfunction. Circulation. 1998;98:2687-94.

12. Alam M, Hedman A, Nordlander R, Samad B. Right ventricular function before and after an uncomplicated coronary artery bypass graft as assessed by pulsed wave Doppler tissue imaging of the tricuspid annulus. Am Heart J. 2003;146: 520-6.

13. Reynolds HR, Tunick PA, Grossi EA, Dilmanian H, Colvin SB, Kronzon I. Paradoxical septal motion after cardiac surgery: a review of 3,292 cases. Clin Cardiol. 2007;30:621-3.

14. Hedman A, Alam M, Zuber E, Nordlander R, Samad BA. Decreased right ventricular function after coronary artery bypass grafting and its relation to exercise capacity: a tricuspid annular motion-based study. J Am Soc Echocardiogr. 2004; 17:126-31.

15. Keyl C, Schneider J, Beyersdorf F, Ruile P, Siepe M, Pioch K, et al. Right ventricular function after aortic valve replacement: a pilot study comparing surgical and transcatheter procedures using 3D echocardiography. Eur J Cardiothorac Surg. 2016;49:966-71.

16. Bhaya M, Sudhakar S, Sadat K, Beniwal R, Joshi D, George JF, et al. Effects of antegrade versus integrated blood cardioplegia on left ventricular function evaluated by echocardiographic real-time 3-dimensional speckle tracking. J Thorac Cardiovasc Surg. 2015;149:877-84, e1-5.

17. Buckberg G, Athanasuleas C, Saleh S. Septal myocardial protection during cardiac surgery for prevention of right ventricular dysfunction. Anadolu Kardiyol Derg. 2008;8(Suppl 2):108-16.

18. Buckberg G, Hoffman JI. Right ventricular architecture responsible for mechanical performance: unifying role of ventricular septum. J Thorac Cardiovasc Surg. 2014;148:3166-71, e1-4. 